\title{
FNREL
}

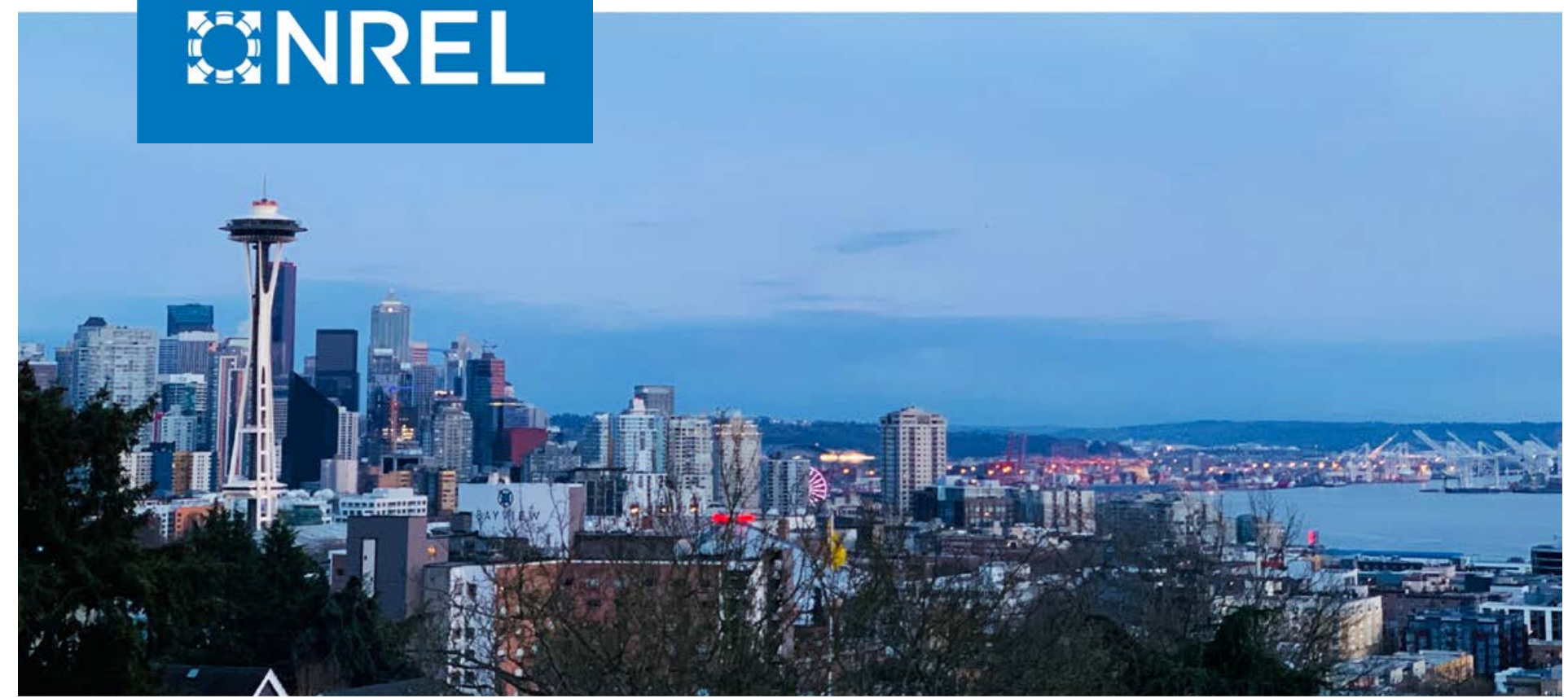

\section{Hydrogen and Fuel Cells for Data Center Applications Project Meeting: Workshop Report}

Genevieve Saur, ${ }^{1}$ Vanessa Arjona, ${ }^{2}$ Amberlie Clutterbuck, ${ }^{2}$ and Eric Parker ${ }^{2}$

1 National Renewable Energy Laboratory

2 U.S. Department of Energy Fuel Cell Technologies Office

NREL is a national laboratory of the U.S. Department of Energy

Office of Energy Efficiency \& Renewable Energy

Operated by the Alliance for Sustainable Energy, LLC

This report is available at no cost from the National Renewable Energy Laboratory (NREL) at www.nrel.gov/publications.
Technical Report

NREL/TP-5400-75355

December 2019 


\title{
GNREL
}

\section{Hydrogen and Fuel Cells for Data} Center Applications Project Meeting: Workshop Report

\author{
Genevieve Saur, ${ }^{1}$ Vanessa Arjona, ${ }^{2}$ Amberlie Clutterbuck, ${ }^{2}$ \\ and Eric Parker ${ }^{2}$
}

1 National Renewable Energy Laboratory

2 U.S. Department of Energy Fuel Cell Technologies Office

\section{Suggested Citation}

Saur, Genevieve, Vanessa Arjona, Amberlie Clutterbuck, and Eric Parker. 2019.

Hydrogen and Fuel Cells for Data Center Applications Project Meeting: Workshop Report.

Golden, CO: National Renewable Energy Laboratory. NREL/TP-5400-75355.

https://www.nrel.gov/docs/fy20osti/75355.pdf.

NREL is a national laboratory of the U.S. Department of Energy Office of Energy Efficiency \& Renewable Energy Operated by the Alliance for Sustainable Energy, LLC

This report is available at no cost from the National Renewable Energy Laboratory (NREL) at www.nrel.gov/publications.

Contract No. DE-AC36-08GO28308
Technical Report

NREL/TP-5400-75355

December 2019

National Renewable Energy Laboratory 15013 Denver West Parkway Golden, CO 80401

303-275-3000 • www.nrel.gov 


\section{NOTICE}

This work was authored in part by the National Renewable Energy Laboratory, operated by Alliance for Sustainable Energy, LLC, for the U.S. Department of Energy (DOE) under Contract No. DE-AC36-08GO28308. Funding provided by U.S. Department of Energy Office of Energy Efficiency and Renewable Energy Fuel Cell Technologies Office. The views expressed herein do not necessarily represent the views of the DOE or the U.S. Government.

This report is available at no cost from the National Renewable Energy Laboratory (NREL) at www.nrel.gov/publications.

U.S. Department of Energy (DOE) reports produced after 1991 and a growing number of pre-1991 documents are available free via www.OSTI.gov.

Cover Photo by Vanessa Arjona: NREL 60272.

NREL prints on paper that contains recycled content. 


\section{Acknowledgments}

The Hydrogen and Fuel Cells for Data Applications Project Meeting was held March 20, 2019, at the Hilton DoubleTree (The Arctic Club) in Seattle, Washington. The meeting was sponsored by the U.S. Department of Energy Fuel Cell Technologies Office. 


\section{Executive Summary}

Data centers have become integral to modern life providing data and services ranging from website hosting to financial services to computing global weather forecast models. The capacity of installations can range from server closets to 100-MW hyperscale data centers and larger. They are projected to account for $3.5 \%$ of the total electricity demand worldwide in the near future. ${ }^{1,2}$

Fuel cells can be used to support critical loads for energy reliability, security, sustainability, and economic benefit. They offer potential for backup or prime power, microgrids, grid support, and combined heat and power applications in the data center.

This project meeting engaged stakeholders from various areas within the data center and hydrogen and fuel cells industries to discuss the suitability and needs of hydrogen fuel cell systems in supplying prime or backup power to critical loads of data centers. By bringing together knowledgeable stakeholders from data center as well as hydrogen storage and fuel cell industries, this workshop aimed to identify the research and development needs to enable hydrogen fuel cells to be a competitive technology in providing power to data centers.

The incumbent technologies that support power needs in data centers are primarily diesel generators (for backup power) and electricity from the grid (for prime power). Therefore, incorporating hydrogen and fuel cells in a data center will have to meet or exceed the performance and value offered by incumbent technologies. Two key challenges will be robust hydrogen supply and storage, especially in prime power applications for data centers. However, benefits include reduced air and noise pollution as compared to diesel generators and microgrid capabilities in prime power.

Three scenarios were developed to help understand the challenges and potential path towards increased adoption. In the near term, backup power and backup power with grid support offer solutions that would not necessitate substantial changes for the industry. The hydrogen supplies currently available would support this level of usage. In the long term, prime power is seen as the ultimate goal and where more benefits could be realized. Potential benefits include carbon-free power with full microgrid capabilities, thermal integration for increased total efficiency, and cost savings from elimination of some of the backup systems or design simplification. However, the hydrogen required for prime power for a hyperscale data center is on the order of 30 tonnes/day for a $20-\mathrm{MW}$ data center, which is the low-end modular size for hyperscale computing.

There are specific factors that drive the decision of altering the way in which data centers power their operations. Uptime is a very high priority because downtime can mean substantial financial losses. Reliability and redundancy are extremely important. Keys to industry acceptance include comfort in the technology, standardized design and equipment for the whole systems that are

\footnotetext{
${ }^{1}$ Pierre Delforge, “America’s Data Centers Consuming and Wasting Growing Amounts of Energy” (Natural Resources Defense Council, 2015), http://www.nrdc.org/energy/data-center-efficiency-assessment.asp.

2 Annual Energy Outlook 2019 (U.S. Energy Information Administration, 2019), Table: Electricity Supply, Disposition, Prices, and Emissions. Case: Reference case, https:/www.eia.gov/outlooks/aeo/data/browser/\#/?id=8$\underline{\mathrm{AEO} 2019 \& \mathrm{cases}=\mathrm{ref} 2019 \& \text { sourcekey }=0 .}$.
} 
readily available, and a "big industry name" to adopt it. Some drivers that could accelerate the adoption of hydrogen and fuel cell technologies in data centers would be the inability to permit diesel generators, a demonstration of the technology in this application such that the risk to the company is reduced and comfort is increased, and concrete commitments as part of corporate strategy to use green or renewable energy. 


\section{Table of Contents}

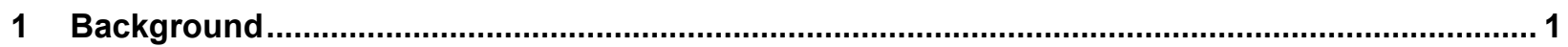

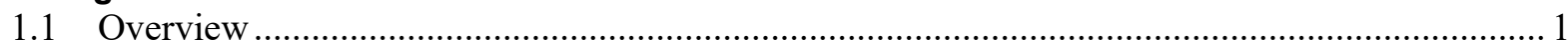

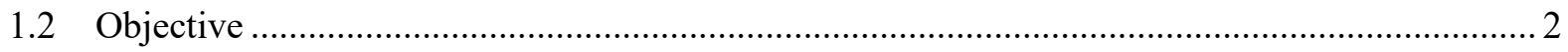

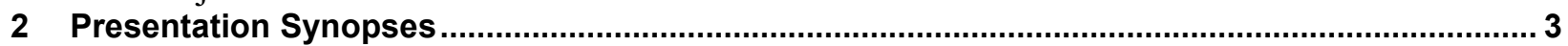

2.1 Welcome, Introductions, Opening Remarks and Workshop Objective-Ned Stetson (DOE) ..... 3

2.2DOE Fuel Cell Technologies and H2@Scale Overview-Dimitrios Papageorgopoulos (DOE).3

2.3 Business Case Analysis - Genevieve Saur (NREL) ................................................................. 3

2.4 The Hydrogen Data Center Proof of Concept - Steve Hammond (NREL) ............................... 4

2.5 In-Rack Direct DC Powering of Servers with Solid Oxide and Proton Exchange Membrane Fuel Cells_-Jack Brouwer (UCI) ................................................................................................... 4

3 Breakout Session 1 Findings_-Industry Considerations, Requirements, and Needs ................ 6

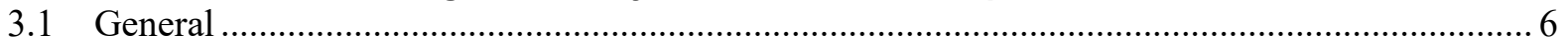

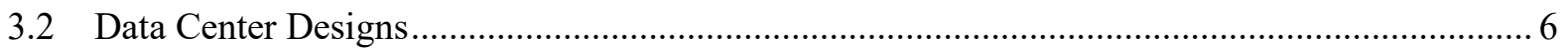

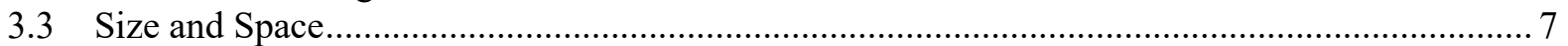

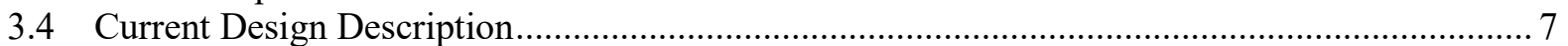

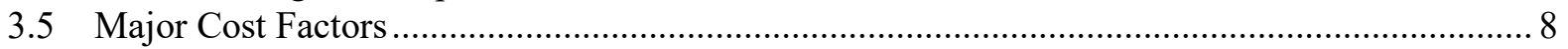

3.6 Industry Inertia to New Technology Considerations................................................................... 9

4 Breakout Session 2 Findings-Applicability of Hydrogen and Fuel Cell Systems to Meet Data

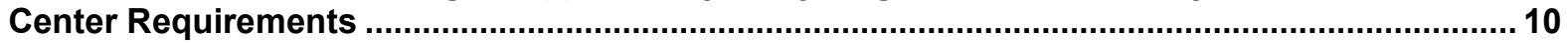

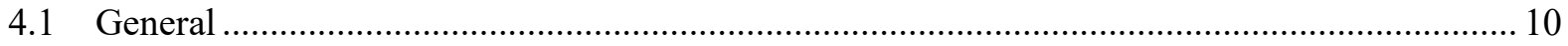

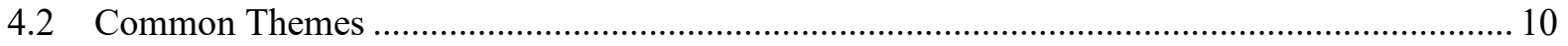

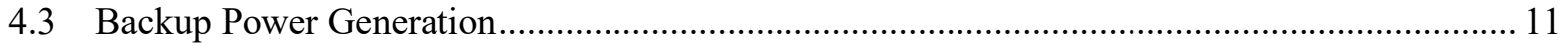

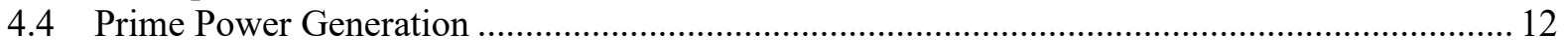

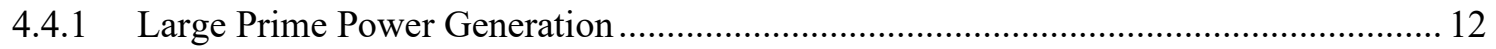

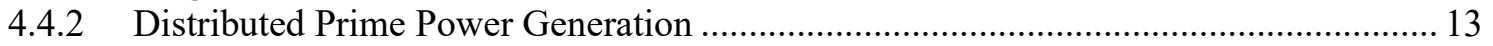

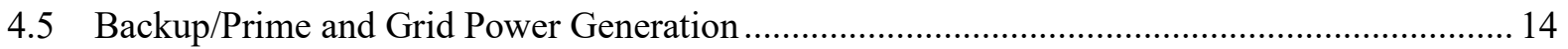

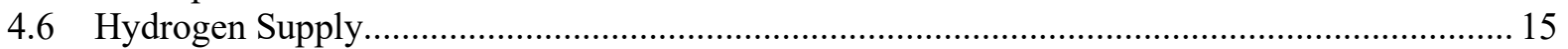

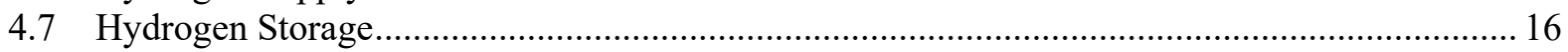

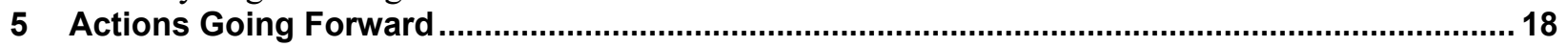

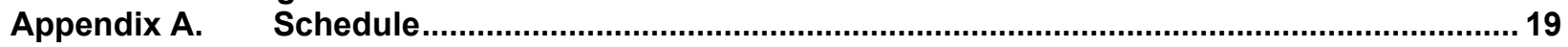

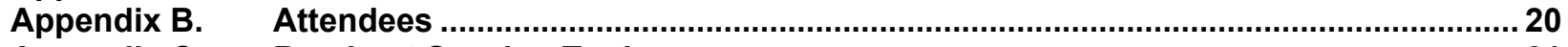

Appendix C. Breakout Session Topics …............................................................................... 21 


\section{Background}

\subsection{Overview}

Fuel cells can be used to support critical loads for energy reliability, security, sustainability, and economic benefit. Data centers have become critically important for a wide range of data services. In 2020, they are expected to account for 3.5\% of the total electricity demand worldwide, ${ }^{1,2}$ and that share is projected to increase exponentially as more industries, sectors, and individuals turn to digital platforms to carry out routine daily activities. ${ }^{3}$ Given the projected demand increase for data-based services and commensurate power consumption, data centers are looking at more cost-effective, sustainable, and reliable ways to power their operations. Hydrogen and fuel cells can be an option to help meet those needs and to serve as an integration option with a range of potential benefits. There are several integration strategies that could be adopted for different situations:

- Prime power - A larger capacity fuel cell situated adjacent to and outside of the data center sized to meet the critical loads and electrical integration with optional thermal integration.

- Prime distributed - Smaller fuel cells electrically integrated at the rack level inside the data center with the option of thermal integration.

- Backup - Either a larger capacity fuel cell or distributed fuel cells used as backup and sized to meet the critical loads of the center.

Fuel options could include on-site hydrogen storage (delivered in tube trailers), intermediary fuels, or hydrogen infrastructure by pipeline, delivery, or on-site production.

This project meeting engaged stakeholders within the data center, fuel cells, and hydrogen industries to discuss the suitability and needs of hydrogen fuel cell systems in supplying prime or backup power to critical loads of data centers. The workshop program included introductory presentations from the U.S. Department of Energy's (DOE's) Office of Energy Efficiency and Renewable Energy's (EERE's) Fuel Cell Technologies Office (FCTO) to set the stage. The National Renewable Energy Laboratory (NREL) and the University of California, Irvine (UCI) provided in-depth presentations on specific projects that demonstrated the potential and applicability of this technology to data centers.

There were two breakout sessions to provide a forum for open dialogue and discussion. These breakout sessions were organized into three groups and each was provided the same topic for discussion. The attendees were assigned groups to ensure appropriate representation from different backgrounds and perspectives. The first breakout session focused on identifying scenarios to cover a range of data center requirements and needs as well as industry-level considerations. The second breakout session focused on the applicability of hydrogen and fuel cells in meeting the power needs of the scenarios identified in the first breakout session. This report summarizes the findings, discussion points, and conclusions from these breakout sessions.

\footnotetext{
${ }^{3}$ Arman Shehabi, Sarah Smith, Dale Sartor, Richard Brown, Magnus Herrlin, Jonathan Koomey, Eric Masanet, Nathaniel Horner, Inês Azevedo, and William Lintner, United States Data Center Energy Usage Report (Berkeley, CA: Lawrence Berkeley National Laboratory, 2016), LBNL-1005775, doi:10.2172/1372902.
} 
In addition to the report, introductory presentations, agenda, and breakout session topics are available on the workshop proceedings web page. ${ }^{4}$

\subsection{Objective}

The purpose of the meeting was to evaluate the application and suitability of hydrogen fuel cells for primary/backup power for data centers by engaging with relevant stakeholders. Experts from data center, hydrogen storage, and fuel cell industries identified the research and development (R\&D) needs to enable hydrogen fuel cells to be a competitive technology that is affordable, reliable, and resilient. Discussions included overcoming gaps in understanding, setting achievable metrics, and identifying opportunities and barriers for adoption. Feedback from industry and key stakeholders will then be used to ensure component developers can eventually meet the needs of these emerging applications. The expected outcome of the meeting is to identify appropriate activities for DOE federal funding to bridge early market hydrogen and fuel cell technologies with data center infrastructure.

The schedule and list of attendees is in Appendix A and Appendix B, respectively.

\footnotetext{
${ }^{4}$ Proceedings available at https://www.energy.gov/eere/fuelcells/hydrogen-and-fuel-cells-data-center-applicationsproject-meeting.
} 


\section{Presentation Synopses}

\subsection{Welcome, Introductions, Opening Remarks and Workshop Objective-Ned Stetson (DOE) ${ }^{5}$}

The opening remarks served to ground the meeting with information regarding the current state of data centers, their energy usage, trends in efficiency, and their growth as an important sector for energy technologies. Refer to Section 1.2 for more detail on the workshop objectives.

\subsection{DOE Fuel Cell Technologies and H2@Scale Overview_Dimitrios Papageorgopoulos (DOE) ${ }^{6}$}

Hydrogen can be produced from a diverse portfolio of domestic sources. Fuel cell shipments have been increasing worldwide due to the introduction of light-duty vehicles, forklifts, buses, backup power, and stationary power. The markets and applications are a worldwide endeavor. The emerging market is now in medium-duty trucks and long-range, heavy-duty vehicles.

DOE's FCTO has a strong commitment to furthering the technology with dedicated funding for research and other activities that have spanned 32 states and the District of Columbia. H2@Scale is a DOE initiative that would enable affordable, reliable, clean, and secure energy across sectors. DOE provides leadership for H2@Scale through a consortia approach that leverages national labs and industry enabling partnerships for early R\&D activities and demonstration, deployment, and commercialization activities. The H2@Scale consortium has more than 20 current projects with more opportunities forthcoming.

\subsection{Business Case Analysis-Genevieve Saur (NREL) ${ }^{7}$}

This techno-economic analysis looked at the long-term vision of a carbon-free data center. The analysis considered the supply side of renewable hydrogen production and storage. The model looked at regional variations in renewable generation, equipment sizing, cost, and near- and long-term scenarios, including:

- $100 \%$ data center power supplied from various renewable sources.

- Data center power load shared between on-site renewable electricity and renewable hydrogen used by fuel cells.

- Data center power purchased on a grid connection with the opportunity to sell back based on usage of on-site renewables.

- Data center power from $100 \%$ hydrogen supplied by natural gas.

\footnotetext{
${ }^{5}$ Ned Stetson, "Hydrogen and Fuel Cells for Data Center Applications: Meeting Introduction" (2019), https:/www.energy.gov/sites/prod/files/2019/04/f61/fcto-data-center-workshop-2019-stetson.pdf.

${ }^{6}$ Dimitrios Papageorgopoulos, "Overview: DOE Fuel Cell Technologies and H2@Scale” (2019), https://www.energy.gov/sites/prod/files/2019/04/f61/fcto-data-center-workshop-2019-papageorgopoulos.pdf.

${ }^{7}$ J. Kurtz, Z. Ma, S. Hammond, T. Cader, K. Wipke, and G. Saur, "Renewable Hydrogen for a Carbon-Free Data Center," https://www.energy.gov/sites/prod/files/2019/04/f61/fcto-data-center-workshop-2019-saur.pdf.
} 


\subsection{The Hydrogen Data Center Proof of Concept-Steve Hammond $(\mathrm{NREL})^{8}$}

Project partners NREL, Daimler AG, Hewlett Packard Enterprise (HPE), and Power Innovations rethought power delivery and distribution within data centers. A novel proof-of-concept "hydrogen-based" carbon-free data center was developed using key building blocks such as renewable energy sources, electrolyzers, hydrogen storage, and hydrogen fuel cells. The data center design evaluated hydrogen fuel cells packaged in a row-scale to power IT racks that distributed hydrogen instead of electricity into the facility.

The objectives of this effort were:

- Develop a novel, integrated, carbon-free data center proof-of-concept design based on automotive-scale hydrogen fuel cells and renewables for power.

- Increase manufacturing volume and decrease cost to advance fuel cell deployment and adoption in diverse applications beyond the transportation sector.

- Accelerate market transformation with modest DOE investments.

- Initiate development of codes and standards for safety and reliability of hydrogen fuel cells in data centers.

- Explore capturing and reusing waste heat from IT racks and fuel cells for space heating applications; or to drive adsorption chillers to generate chilled water.

\subsection{In-Rack Direct DC Powering of Servers with Solid Oxide and Proton Exchange Membrane Fuel Cells_Jack Brouwer (UCI) ${ }^{9}$}

Jack Brouwer, Professor of Mechanical and Aerospace Engineering and Director of the National Fuel Cell Research Center at UCI, presented results from UCI's work with Microsoft Corporation to investigate the direct DC powering of servers with proton exchange membrane fuel cells and solid oxide fuel cells. Their collaborative research showed that a direct generation method that places fuel cells at the rack level, just inches from the servers, limits the failure domain to a few dozen servers. Other advantages of placing the fuel cells at the rack level included lower-voltage DC connections and the elimination of expensive data center equipment, such as power distribution units, high-voltage transformers, expensive switchgear, AC/DC power supplies, and backup generators. The research showed that both proton exchange membrane fuel cell and solid oxide fuel cell systems could follow the dynamic power demands of servers while operating. However, the fuel cell systems could need some support from battery energy storage systems for the extreme transients experienced during a cold startup. The overall efficiency of delivering power to the servers starting from natural gas was shown to be $29.5 \%$. This is compared to the utility grid network provision of power also starting from natural gas at $17.5 \%$ efficiency.

\footnotetext{
${ }^{8}$ Steve Hammond, "The Hydrogen Data Center Challenge" (2019), https://www.energy.gov/sites/prod/files/2019/04/f61/fcto-data-center-workshop-2019-hammond.pdf.

${ }^{9}$ Jack Brouwer, "In-Rack Direct DC Powering of Servers with Solid Oxide and Proton Exchange Membrane Fuel Cells" (2019), https://www.energy.gov/sites/prod/files/2019/04/f62/fcto-data-center-workshop-2019-brouwer.pdf.
} 
Prof. Brouwer also presented a vision of a 100\% zero-emission future in which all primary energy comes from the sun, wind, wave, geothermal, and other renewable sources. This vision uses only zero-emission electrochemical energy conversion systems, such as batteries, electrolyzers, and fuel cells, to complement the renewable sources, and uses only zero-emission energy carriers, such as hydrogen and renewable gases and liquids. He showed the massive storage potential of hydrogen and the seasonal storage that could be enabled by using existing natural gas resources (e.g., underground gas storage facilities) to store pure hydrogen. He also noted lithium-ion battery technology could present some challenge for massive or seasonal energy storage due to self-discharge and lithium and cobalt resource availability. His analysis projected that installing 20 square miles of solar panels in the desert, followed by production of pure hydrogen by electrolysis and the use of the existing natural gas system, would increase California renewable generation by $40 \%$. 


\section{Breakout Session 1 Findings-Industry Considerations, Requirements, and Needs}

Participants did not reach a consensus during the first breakout session. The following sections intentionally reflect this non-consensus as a way to accurately provide all perspectives.

\subsection{General}

Data center owner/operators are for-profit businesses and will therefore be conservative with new technologies that might affect their bottom line. This is especially true if the current methods work and are relatively inexpensive and reliable. Adoption of a new technology is more likely if a large and/or established data center business adopts it first.

There are several factors that could cause a shift away from the usual data center design. Data centers have large space and power requirements; therefore, deciding their locations is partly reliant on regional conditions with respect to land and labor costs, access to affordable power, and a business-favorable government. Each computer placed in the data center can generate tens of thousands of dollars; therefore, space considerations are key when incorporating new technology systems. Redundancy is generally important and battery or diesel generators are currently the norm. Air permitting of the diesel backup generators could become stricter in certain regions, making the case for incorporating hydrogen and fuel cells stronger.

There were also promising cases where companies had established corporate strategies to increase the use of non-carbon/green fuels. A few had already moved to $100 \%$ renewables and other co-locators were moving in that direction. This strengthens the justifications for using green hydrogen or sites near wind or other renewable electricity.

\subsection{Data Center Designs}

Participants identified four data center designs but pointed to the changing nature of data center designs in the last couple of years. Initially, each company and co-locator had their own data center designs and centralization. Recently, there are some companies moving toward relying on several data center sizes and locations to provide redundancy and improve service response times. Therefore, a standard or general data center design is becoming less common.

The different data center designs have some overlapping characteristics. The four designs are described as follows:

- High performance computing - This design is a high-speed computing-intensive application that processes complex algorithms used in the fields of science, engineering, and business. High performance computing data centers tend to have denser loads per rack, $70-100 \mathrm{~kW}$, but are a small percentage of all data center power consumed.

- Hyperscale, single customer-This design can be scaled appropriately based on a single company's business needs (cloud services, big data, distributed or grid computing). Hyperscale, single customer data centers are modularly designed to allow for the seamless increase of computing capacity. Sizes range from $100 \mathrm{~kW}$ to $100 \mathrm{MW}$. Redundancy occurs at the data center level and as part of a larger strategy (i.e., data mirroring). 
- Hyperscale, co-location-This design is scaled appropriately based on the individual needs of multiple customers that contract from a third-party data center company. Customers are often smaller, regional entities. Redundancy generally occurs at the data center. Thermal and electrical isolation between customers is an important design consideration.

- Point of presence servers/mini data centers/micro data centers - This design is smaller ( $50 \mathrm{~kW}$ to $2 \mathrm{MW}$ ). These data centers may be operated by a larger hyperscale entity off-site, located on the property of another business renting the space, or standalone. Reliability is a lower priority because the design is intended for geographic presence to improve response times. Backup power is typically supplemented with a battery sized for 5 minutes and a diesel generator.

The number of prime power installations for the different data center designs are estimated to be:

- $100,000+$ of $50-\mathrm{kW}$ unit installations

- $10,000+$ of $1-\mathrm{MW}$ to $30-\mathrm{MW}$ unit installations with 10-year life cycles

- $100+$ of 100-MW unit installations with 10-year life cycles.

\subsection{Size and Space}

There is a broad range of capacities for data centers between $50 \mathrm{~kW}$ and $100 \mathrm{MW}$. However, there were some overarching themes to data center sizes. Hyperscale computing customers can design their data centers with a customizable number of 20-30 MW modules. This hyperscale design allows for 30-100 kW/rack and up to $200 \mathrm{~kW} /$ row with the option for higher energy intensities for high performance computing.

The footprint cost of the data center and its supporting systems is one of the factors that must be considered. An estimated $40 \%$ of the building footprint is dedicated to electrical infrastructure. Electrical load power densities range from $200 \mathrm{~W} / \mathrm{ft}^{2}$ (co-location data centers) to $1,000 \mathrm{~W} / \mathrm{ft}^{2}$ (high-end, high-performance computing), which require multiple points of step-down power conversions where power is transferred from the electric utility lines to IT racks that run on AC power.

Data centers currently rely on grid power with distributed electricity. Each rack can be powered by up to four copper-based electrical cables that are several inches in diameter. In order to achieve maximum uptime or availability, redundancy must be built into the design. Maximum levels of redundancy are achieved using duplicate electrical infrastructure with backup provided by either multiple utility interconnections or an interconnection to the battery/diesel generator systems. The electrical infrastructure (power conversion equipment and copper wiring) imposes significant cost and space requirements for data centers. Today's AC power distributions have standardized options for IT racks and data centers.

\subsection{Current Design Description}

Redundancy is one of the top priorities for most data centers. This is generally termed as $n+1$ or $2 \mathrm{~N}$, where $\mathrm{n}+1$ refers to adding one component to support a single failure and $2 \mathrm{~N}$ refers to a fully redundant mirrored system. Participants mentioned that in practice this translates to $5+1$ or $10+1$ racks per backup system for some data centers. The on-site backup systems provide $24-48$ hours 
of power from battery and diesel generator systems, which meets a tier 3 data center compliance standard. The battery is generally sized to run for 5 minutes before the diesel generator takes over. Current diesel systems are between 2.5 MW and $3 \mathrm{MW}$ and are coupled into $20 \mathrm{MW}$ backup modules for larger customers. The system efficiency of the uninterruptable power supply, defined as the amount of input power that directly powers the load and does not include the efficiency of the diesel generator, is about $92 \%-95 \%$, due to transforming switches.

The backup power required is needed for both the IT loads and auxiliary systems. Cooling is an important aspect of data center design and must be backed up along with the actual IT loads. The fans, pumps, and other equipment are all required to work in tandem for reliable operation. It is not enough to provide backup for the IT racks alone because they cannot be run without auxiliary systems - the design must be all-inclusive. A fuel cell-powered data center and backup design must include all these aspects.

For on-site fuel storage, diesel is favored by the industry due to its high energy density, low cost, and low space requirements. This current industry standard will likely continue as long as diesel has no competition. However, air permitting of diesel generators has become increasingly difficult on a state and regional level. It is conceivable that diesel generators could become prohibited in some places, which would allow for alternative fuels such as hydrogen to become competitive.

Finally, monitoring obsolescence rates of current data center equipment could help understand the design cycles and replacement requirements to retrofit existing modules or when designing new data centers. The estimated time for replacements and upgrades are:

- 3 years for IT equipment

- 5 years for batteries

- 5-10 years for power distributors

- 30 years for generators.

\subsection{Major Cost Factors}

Although powering a data center with hydrogen fuel cells could offer an integrated, potentially cost-effective solution, industries are apprehensive to adopt the technology. This is primarily due to the predictable cost and reliability of current data center designs. Therefore, general experiential knowledge about alternative designs and technologies (energy storage, fuel source) is typically not an industry priority.

The roadblock to integrating fuel cells as prime power is the low cost of traditional grid energy $(\$ 0.03 / \mathrm{kWh})$, though switching to alternative grid energy could lead to a $40 \%$ cost reduction. For example, data centers use $\$ 3$ million worth of traditional grid energy on redundancy alone. The total cost of energy used by a data center must account for both electrical and thermal systems. One alternative to grid electricity would be to combine heat and power integration to cool data center equipment. While fuel cells generate more heat on-site than grid electricity does, there are two considerations: 
1. Higher quality heat from a large fuel cell outside the data center might provide cooling through an adsorption chiller as well as provide heat to other thermal systems for humidity control.

2. Fuel cells integrated at the rack or row level inside the data center would allow significant reduction of power electronics for distributing electricity into the data center replacing it with hydrogen piping; the power infrastructure is a major source of data center heat loads, additionally low-temperature fuel cells could be integrated into watercooled data center designs.

In order to consider fuel cells as backup systems, they need to be cost competitive and/or offer significant advantages over uninterruptable power supply from batteries or diesel systems. A disadvantage of current battery uninterruptable power supply systems is they require a significant amount of maintenance. While upfront capital cost of today's system is an important consideration, maintenance is also a significant operational cost. Alternative systems, such as fuel cells, that lower the cost of maintenance would be of value. Performing a total cost of ownership analysis to account for upfront costs and operation and maintenance would be valuable.

\subsection{Industry Inertia to New Technology Considerations}

Most of the inaction to new technology comes from the novelty of the hydrogen fuel cell industry. Several participants said their company would consider fuel cell technology if a wellknown industry name were to first demonstrate a proof of concept. This is because a data center's core business is providing data services, not power, especially since $100 \%$ uptime is required to prevent revenue loss. Co-location data centers would also require approval from all their customers before piloting a demonstration. Finding the right opportunity is key to growing experience and comfort in a new technology.

Some fuel cell integration options would require radical redesigns of the modern data center. Other design options are less disruptive, but the benefits would be less measurable. Metrics must be defined in terms of the impacts and benefits from a perspective of capital cost, supply chains, maintenance, and operation requirements for reliability and redundancy. The whole life cycle of the data center must be considered, not just capital costs. 


\section{Breakout Session 2 Findings-Applicability of Hydrogen and Fuel Cell Systems to Meet Data Center Requirements}

\subsection{General}

Participants discussed three general scenarios (near-term, mid-term, and long-term) using hydrogen fuel cell power providing backup, prime/backup, and prime power with ancillary support. There was no agreed upon first step for fuel cell integration. However, different integration scenarios offer different levels of commitment and benefits. Several of the scenarios will require significant redesign of the current systems. To reiterate, the industry as a whole will likely follow if a large company takes the first step. A promising factor is that fuel cell technology has already been proven in the transportation and space sectors. Ultimately, cost will remain a decisive factor integrating fuel cells into data center designs.

\subsection{Common Themes}

There were several crossover issues and concerns that were applicable to several scenarios. An important factor in integrating fuel cells into data centers was understanding the competition. Incumbent technologies are diesel generators for backup and grid electricity for prime power. Current electricity costs for prime power are $\$ 0.03 / \mathrm{kWh}$ with $\$ 0.05 / \mathrm{kWh}$ accepted as a premium on green power. For comparison, diesel generators are on the order of $\$ 1 / \mathrm{W}$. Therefore, the total cost of ownership must be less expensive than the incumbent technologies or offer other compelling benefits. In addition, it should take into account initial capital costs, building infrastructure, system efficiency, maintenance, and operation costs. A redesign of data centers that incorporate fuel cells will also need new hardware and configurations to match the same operating characteristics as today's data centers. These reconfigurations will also affect the cost.

Scalability is also a key driver when considering modular hyperscale designs. This affects both the current and future design of the electronics as well as any thermal integration. For the hyperscale computing application, there was some consensus on testing 20-30 MW module designs. Testing mini data centers between $100 \mathrm{~kW}$ and $2 \mathrm{MW}$ had wider acceptance. Natural gas was also seen as a potential bridge to green hydrogen, which would allow renewable hydrogen systems to scale up. Future data centers interested in integrating hydrogen fuel cells could build within close proximity to natural gas pipelines.

There were questions about the auxiliary system requirements. This included whether the size of the battery could be reduced or eliminated; if the grid connection would be needed in addition to the hydrogen infrastructure; if the natural gas infrastructure would be adequate and reliable enough; or what the redundancy would look like for the different scenarios. Most of these questions pointed to a need for detailed design(s) that could specify the energy system and building infrastructure for the different scenarios. To reiterate, the key questions and concerns centered on costs, standards, and supply chains and were discussed in further detail during the second session.

From the perspective of the fuel cell manufacturer, if the same fuel cell design could be used across several applications, such as automotive and data center power, then there would be a cost 
benefit during the development, production, and supply phases. However, cross-application would depend on the requirements of each application in terms of cost, durability, and efficiency. These questions can start to be answered once scenarios are identified. Along the same lines, multiple hydrogen end uses in the same geographical area would help simplify hydrogen infrastructure for the companies supplying fuel. This might entail a data center being placed in general proximity to a warehouse using fuel cell lift trucks or a fuel cell truck depot. Finding cross applications, whether general or localized, will help bring down overall costs and benefit other businesses in the hydrogen supply chain.

Standard IT racks support AC power; however, fuel cells operate in DC mode. A switch to DC power would offer some substantial benefits for fuel cell integration and overall data center infrastructure. This move would necessitate a radical redesign of the data center. First, changes to the supply chain would have to be made because DC components for data centers are uncommon. Second, technician safety training would have to occur because most electricians are not trained to work in DC mode. These issues would need to be addressed before a pilot project would move into mainstream deployment.

Each scenario has its own benefits when integrated with fuel cells. The fuel cell energy system offers a microgrid solution with potential for being completely renewable or being integrated with a natural gas infrastructure. The microgrid capabilities could also provide ancillary services for increasing renewable penetration in a geographical location. Unlike diesel generators, fuel cells would not require air or noise permits, though they would require other safety permits. The fuel cell system can operate as a dynamic part of an emerging regional energy system or as an island microgrid that offers clean, quiet power.

\subsection{Backup Power Generation}

The first scenario examined was integrating fuel cells for backup power. Participants suggested this could be a near-term, small step to gain fuel cell experience. This change would be the least disruptive to the industry, as long as the replacement solutions met energy requirements with similar operating characteristics as diesel. The capacity of a diesel generator is $2.5-3 \mathrm{MW}$, while hydrogen fuel cell capacities come in a range of sizes and have been coupled into the MW range that would be comparable to diesel generators. For large-scale computing the data center module size is 20-30 MW. This high estimate for a module would require 55-130 tonnes of hydrogen for 48-72 hours of backup power. This amount could be met by today's hydrogen suppliers, but only for infrequent backup use; see Section 4.6 for more information. However, this amount of hydrogen would require considerable space for storage.

An advantage of integrating fuel cells as a backup power source means a complete redesign of the data center is not necessary. Fuel cells would replace diesel generators by using similar electrical infrastructure, redundancies, and support systems already in place. An inverter from $\mathrm{AC}$ to DC power would also have to be added. Other favorable characteristics of using fuel cells include their robust durability and fast startup times, which would decrease the size of the battery. This design could be incorporated or retrofitted into existing data center infrastructure.

Gaseous or liquid hydrogen would have to be delivered, which would require a larger storage footprint than liquid diesel due to the density of hydrogen. It is estimated that up to two to three 
days' worth of hydrogen would have to be stored, and therefore bulk hydrogen storage options would have to be considered.

In terms of the upfront capital cost of a hydrogen fuel cell system compared to diesel generators, hydrogen supply and storage would be more expensive. However, use of hydrogen from natural gas would be generally acceptable as a near-term alternative to renewable hydrogen, but the ultimate goal would be fully renewable hydrogen. The hours of operation for this scenario would be an estimated 100 hours per year and the storage costs would have to compete against $\$ 1 / \mathrm{W}$. There could be some savings on maintenance and repairs because fuel cells require less upkeep than diesel generators. However, operation and maintenance services would have to be readily trained and available. In conclusion, fuel cells would be more costly than diesel generators until overall cost for fuel cells and hydrogen production, delivery, and storage decreases. However, one factor that would favor conversion to fuel cells would be if environmental regulations banned the use of diesel generators. This could happen on a regional or state level and would provide a niche opportunity for fuel cells to be accepted in the data center industry.

While replacing diesel generators with fuel cells would most likely be the first method of adoption, it would not be an economic solution until the costs of fuel cells and hydrogen were reduced. Because the operation hours of backup fuel cells would be low, durability and efficiency would not be a key driver for the industry to shift toward incorporation. Therefore, fuel cell manufacturers must find methods to reduce the cost, potentially at the expense of durability and efficiency.

\subsection{Prime Power Generation}

The prime power application can be split into two categories: large prime power and distributed prime power. The similarities and differences are discussed in sections 4.4.1 and 4.4.2. Prime power systems must operate $24 / 7$ for 365 days per year. Therefore, the durability requirements must be on the order of 15 years or 130,000 hours. Daily operation would require constant fuel supply and regular delivery, as well as enough on-site storage for 24-72 hours of backup power.

An advantage of prime power is that thermal integration can be possible for both high- and lowtemperature fuel cells. This offers some opportunities for combined heat and power and greater overall efficiency. Some thermal system options include absorption chillers for cooling or dehumidification systems. The competition for prime power was determined to be grid electricity at $\$ 0.03 / \mathrm{kWh}$ or $\$ 0.05 / \mathrm{kWh}$, which would be an accepted premium for green power. In a combined heat and power application this would be amended to include the total energy costs rather than just electricity.

\subsubsection{Large Prime Power Generation}

One option for integration would have large, centrally located fuel cells placed outside of the data center building. These could be either high- or low-temperature fuel cells and could be operated together. The fuel cells would distribute electricity into the data center and would offer on-site generation instead of electricity from the grid. One advantage to this approach is that a massive redesign of the data center electrical infrastructure would not be required. The on-site generation offers opportunities for combined heat and power, potential for grid independence, and cost savings by eliminating some parts of the uninterruptable power supply backup system. 
On-site generation could be designed to use natural gas or hydrogen. Many fuel cells systems are currently configured to run off natural gas, ${ }^{10}$ and a data center could take advantage of the extensive natural gas infrastructure already in place in the United States. Hydrogen fuel cells could also be used with either on-site steam methane reforming of natural gas, on-site electrolysis, or delivered hydrogen. Delivered liquid hydrogen and hydrogen pipelines would likely be more appropriate for large prime power generation.

On-site hydrogen storage for fuel backup or supply issues could take several forms. Delivered liquid hydrogen would have greater energy density than gaseous storage and thereby take up less space. This is the most well-known bulk storage method, but the number of deliveries to the site would have to be estimated based on the load and projected expansion of the data center. Other forms of storage could include geologic caverns or other chemical storage mechanisms.

However, these last two options are not as well researched and therefore only suitable suggestions for medium- and long-term plans. A green alternative for the on-site production of hydrogen could also be electrolysis. However, there were some questions whether the sizes available today would be adequate to support the daily needs of up to 25-45 tonnes of hydrogen for a 20-30 MW continuous load. The daily hydrogen requirement would depend a lot on the type of fuel cell used and how readily it can be ramped up and down, turned on/off, the thermal integration, and the expected renewable electricity profiles.

Additionally, grid connections could be used for either backup or to provide grid auxiliary services. The economics of maintaining a grid connection would need to be analyzed on a case by case basis to estimate the potential cost of demand charges versus compensation for providing grid services.

The economics of a large prime power generation scenario would depend on the relative price of natural gas to electricity, whether any combined heat and power options could be used, and how redundancy and backup systems would be designed.

\subsubsection{Distributed Prime Power Generation}

This option would distribute prime power by integrating each rack or row with its own fuel cell. This means hydrogen would be distributed into the data center instead of electricity. The racks could be connected to one another by AC or DC power, but would require a DC electrical interface, or DC bus, for the fuel cell. This is a radical data center energy infrastructure redesign, but it offers some compelling advantages, including:

- The building infrastructure would be significantly simplified. It was estimated that $40 \%$ of the data center footprint and cost were in the electrical distribution components and equipment. Hydrogen distribution would significantly reduce both the cost and footprint. Much of the traditional power conversion hardware and copper cabling could be replaced with simple stainless-steel piping and exhaust vents.

- Distributed power provides built-in redundancy and ease for maintenance.

\footnotetext{
${ }^{10}$ Some fuel cell varieties internally reform natural gas and require a feedstock such as natural gas or biogas. Other varieties use external reforming of natural gas and the fuel cell stack is fed pure hydrogen and air. Fuel cell varieties where the stack uses pure hydrogen could run off natural gas or hydrogen, but individual companies may not offer all configurations.
} 
- Uninterruptable power supply battery sizes would be significantly reduced, therefore lowering capital and maintenance cost and time.

- Liquid-cooled data centers could make use of low-quality heat for data center cooling or dehumidification.

- Moving to a DC bus and reducing the building electrical infrastructure dramatically reduces the heat loads in the data center and would increase electrical efficiency for metrics like power usage effectiveness. However, proximity of the fuel cell to the load would be essential to realize savings.

- Certain fuel cell varieties could be more appropriate with designs depending on the requirements for high- or low-quality heating and cooling.

- Proton exchange membrane fuel cells used in current-generation fuel cell electric vehicles are also compatible with this application; therefore, both industries could benefit from increased production rates and reduced costs.

To realize these advantages will take significant effort. The vision would require a radical redesign of data centers with several hurdles to overcome. As with many industries, change can be difficult, especially when it may affect operations of the core businesses.

Redundancy is of prime importance and can be satisfied in several ways. The least economic option, but safest in terms of industry acceptance, would be to have a data center rely on both electrical distribution and hydrogen infrastructure. However, this would be inefficient in terms of cost and footprint and would not be generally recommended. It is expected that a switch to this system would require embracing it fully compared to implementing both designs.

Other forms of redundancy would be equipment duplication. To enable this, parallel hydrogen pipelines could provide distribution redundancy. Distributed fuel cells could provide row power, rather than to individual racks, and be coupled, for instance six fuel cells powering four racks with two spare fuel cells. On-site or delivered hydrogen could be coupled with on-site storage to provide adequate backup supply.

Other hurdles would involve a switch to DC power. A more robust supply chain for DC components would need to be established. Maintenance electricians would require appropriate training because DC current requires different handling procedures than AC current does. Greater adoption of the technology would require these areas to scale up in tandem.

In terms of the redesign, it is expected that a data center would need to commit $100 \%$ to hydrogen and fuel cells to realize cost savings. Some factors that would affect this include placing the distributed fuel cells near the load but in vertical configurations to conserve floorspace. Liquid-cooled data centers could also make use of waste heat. Maintaining a grid connection would require thorough consideration to understand the benefits versus the cost.

\subsection{Backup/Prime and Grid Power Generation}

A smaller, less disruptive step that could provide industry experience with fuel cells would be to include a grid connection in tandem with fuel cells for prime and/or backup power. Participation in grid ancillary services could provide economic incentives, especially as the ancillary markets 
transform with increasing renewable sources. This kind of setup could provide nearer-term opportunities for both the data center industry as well as support grid modernization and increased renewable penetration.

Services could include peak shaving, frequency regulation, and increased demand response. Peak shaving might take the form of 4-6 weeks of operation during 15-minute peak periods. However, benefits of participation would have to be balanced with wear and tear on equipment, possible depletion of on-site fuel storage, and the risk that several events in conjunction could cause unavailability of the system for the data center load. This would likely require liquid hydrogen storage to be used due to the increased, regular demand, which would have its own space and cost implications on-site. There are trade-offs with this scenario that must be analyzed.

\subsection{Hydrogen Supply}

Participants regarded hydrogen supply as a key challenge for prime power applications due to access and reliability. However, natural gas could help alleviate these issues and provide a bridge to a renewable hydrogen supply. Hydrogen supply could take the form of either on-site production or as a gaseous or liquid delivery.

For backup scenarios the hydrogen could come out of the merchant market, currently about 260 tonnes/day for liquid and 15,000 tonnes/day for compressed gas. ${ }^{11}$ The flexibility of the merchant market has become tighter in recent years due to increased forklift and vehicle demands, and aging liquefaction equipment that was built to support NASA in the 1960s. However, four additional liquefiers have been announced in 2018/2019 that would be online in the next 2-4 years, and this may provide some additional flexibility in the merchant market. ${ }^{12,13,14,15}$ There is a balance between increased demand and additional capacity that must be managed. The other option for data centers might be outside of the merchant market where hydrogen sourcing can be mitigated by siting near existing pipelines or in synergy with a regular, large consumer like medium-/heavy-duty trucking, which would aid a bulk chemical company's expansion of production and delivery investments.

For prime power or large, regular usage, on-site production is more likely. On-site production includes both opportunities and concerns. The issues for on-site generation were:

- Chemical plant would need to be on-site.

\footnotetext{
11 "Merchant Hydrogen Plant Capacities in North America" (H2 Tools, 2019), https://h2tools.org/hyarc/hydrogendata/merchant-hydrogen-plant-capacities-north-america, accessed September 3, 2019.

12 "Air Liquide to build first world scale liquid hydrogen production plant dedicated to the supply of Hydrogen energy markets" (Air Liquide, 2018), https://energies.airliquide.com/air-liquide-build-first-world-scale-liquidhydrogen-production-plant-dedicated-supply-hydrogen, accessed September 3, 2019.

13 "Praxair to Build New Liquid Hydrogen Plant in La Porte Texas" (Praxair, 2018), https:/www.praxair.com/news/2018/praxair-to-build-new-liquid-hydrogen-plant-in-la-porte-texas.

14 “Air Products to Build World-Scale Liquid Hydrogen Plant at its La Porte, Texas Facility” (Air Products, 2018), http://www.airproducts.com/Company/news-center/2018/09/0911-air-products-to-build-world-scale-liquidhydrogen-plant-at-laporte-texas-facility.aspx.

15 “Air Products to Build Second Liquid Hydrogen Production Facility in California” (Air Products, 2019), http:/www.airproducts.com/Company/news-center/2019/01/0107-air-products-to-build-second-liquid-hydrogenproductions-facility-in-california.aspx.
} 
- The size of electrolyzers currently available would be a limitation for supplying enough hydrogen for hyperscale computing facilities. For example, a 20-MW data center would require about 30 tonnes/day of hydrogen.

- The land required for electrolysis powered by renewables such as solar or wind would be sizable.

- Locations that support the production of renewable energy may not be favorable in other ways for data centers.

On-site generation from electrolysis and steam methane reforming were considered. A viable solution for prime power and redundancy would include on-site hydrogen generation and storage. This large amount of hydrogen could offer additional benefits such as providing energy to overloaded grids or peak shaving, a process of reducing the amount of energy purchased from utility companies during peak demand hours. It would also allow for thermal integration opportunities. Steam methane reforming could be scaled up quickly to the sizes required for prime power compared to scaling up the use of electrolyzers. The use of natural gas or biogas could be seen as a more feasible near-term solution. Smaller data centers could potentially make enough hydrogen with current electrolyzers, but cost and return on investment would be less favorable. Another option that was considered were locations with negative pricing of electricity, which in turn could make electrolysis more compelling. On-site generation of hydrogen was also seen as a potential income source if there were other hydrogen users in the area. Building a large hydrogen plant could benefit several end users that are in close proximity, such as a data center near a warehouse that uses fuel cell forklifts.

\subsection{Hydrogen Storage}

Most of the scenarios described in the report would require considerable amounts of hydrogen storage. It is expected most sites would incorporate some hydrogen storage into the system even with on-site generation from natural gas or electrolysis. This would be done so there were reserves during on-site generation outages, pipeline problems, or other supply issues.

There were several options discussed for gaseous and liquid hydrogen storage. These included tankers, cryogenic storage, liquid organic hydrogen carriers, and geologic storage. Alternative future methods could include metal hydrides or other chemical storage options.

Several factors must be considered for hydrogen storage, such as storage capacity, footprint, and cost. Delivered hydrogen would have trade-offs due to size and frequency of deliveries, as well as the quantity needed for 24-72 hours of backup power. Each storage mechanism has unique elements and challenges to it. For example, the cost of hydrogen could be a considerably smaller factor than the cost of the storage vessels themselves. Other bulk storage options are discussed below.

- Gaseous tank storage would require a large footprint, especially when compared to higher-density liquid fuels. This type of storage could be appropriate for backup power, but the footprint and cost required for prime power could be prohibitive.

- Cryogenic tanks for liquid hydrogen storage could be suitable for large quantities beyond $500 \mathrm{~kg}$ of hydrogen. However, boil-off effects would need to be considered. The cost of storage, including land, was estimated to be at least $\$ 650 / \mathrm{kg}$ of hydrogen. 
- Geologic cavern storage could be an option in some areas (e.g., along Texas' Gulf Coast, which could serve as backup to the hydrogen pipeline already there), which would allow for much larger storage (over 100,000 kg/hydrogen) compared to gaseous tanks. Caverns have been used for compressed air and natural gas storage, but hydrogen is a smaller molecule and therefore more prone to rapid diffusion.

- Other chemical carriers could be considered, but not at the sizes required for a large data center. Additionally, the mechanisms of hydrogen release would need to be evaluated for appropriate flow rates. 


\section{Actions Going Forward}

The following were identified as major focal points that must be addressed before data centers will consider adopting the technology.

- A techno-economic analysis of specific scenarios with design details must be performed. This would factor in building modifications and energy infrastructure. A technoeconomic analysis would help to understand operation or upfront capital costs and therefore whether R\&D should focus on efficiency or cost for these applications. Analysis of state tax incentives could also help push early adoption. A techno-economic analysis would also be beneficial in formulating a five- or ten-year plan to increase adoption and acceptance.

- Pilot project(s) by a major industry entity would be necessary for greater industry acceptance where the government would have to take the initial risk. However, there was a difference of opinion on what the best introduction method would be. Backup power would be less disruptive but would not be economic unless diesel generators were no longer permitted. Micro data centers could be lower-risk options for either backup or prime power because of the smaller sizes, reduced hydrogen requirements, and lower reliability expectations. Distributed prime power offers many advantages but was considered the most disruptive. A switch to DC power racks would have implications on design, installation, and maintenance.

- Other pilot project ideas could help early acceptance, such as collaboration with Indian Tribes on tribal lands or with other underserved people and regions.

- Reliable hydrogen supply is key. Hydrogen infrastructure on a large scale needs to be developed. A geographic buildout plan should leverage multiple sectors and applications that would all need or produce hydrogen, such as ammonia plants, steel production plants, or warehouses using a fleet of forklifts or buses.

- Utility companies would have to be engaged in subsequent phases to understand the positive and negative impacts that fuel cell power data centers would have on the grid.

- Establishing an industry panel on safety and standards could facilitate the conversion to DC power. This would impact designers and a range of component manufacturers. Standards would reduce costs for custom equipment and designs. A panel would need to include data center designers, fuel cell manufacturers, and component manufacturers. Standards should also include voltage thresholds.

- Training programs are needed for handling DC power equipment.

- System integration R\&D is needed for balance of plant and system cohesion. This would include both electrical and thermal management as well as efficiency options that are optimized for data center applications. Waste heat and water usage should also be addressed.

- $R \& D$ into low-cost bulk storage options is needed. 


\section{Appendix A. Schedule}

\section{Schedule for Wednesday, March 20, 2019}

8:00-8:15 a.m.

8:15-8:30 a.m.

8:30-8:45 a.m.

8:45-9:15 a.m.

9:15-9:30 a.m.

9:30-10:30 a.m.

10:30 a.m.-12:00 pm

12:00-12:45 p.m.

12:45-1:15 p.m.

1:15-1:45 p.m.

1:45-2:45 p.m.

2:45-3:00 p.m.

3:00-4:30 p.m.

4:30-5:00 p.m.

5:00 p.m.
Welcome, Introductions, Opening Remarks, and Workshop Objective: Ned Stetson (DOE)

DOE Fuel Cell Technologies and H2@Scale Overview:

Dimitrios Papageorgopoulos (DOE)

Business Case Analysis: Genevieve Saur (NREL)

The Hydrogen Data Center Proof of Concept:

Steve Hammond (NREL)

Break

Panel I: Data Center Requirements and Priorities-Ned Stetson (DOE) Panelists: Sean James (Microsoft), Roger Tipley (Schneider Electric), Tahir Cader (HPE), Travis Wright (QTS)

\section{Breakout Session I}

Lunch

Joint Session-Report Outs from Breakout I

In-Rack Direct DC Powering of Servers with Solid Oxide and Proton Exchange Membrane Fuel Cells: Jack Brouwer (UCl)

Panel II: Experience with Hydrogen and Fuel Cells for Data Centers-Dimitrios Papageorgopoulos (DOE)

Panelists ${ }^{16}$ : Bob Mount (Power Innovations), Dietrich Thoss (Daimler AG), Brian Chakulski (Doosan Fuel Cell America)

Break

Breakout Session II

Joint Session-Report Outs from Breakout II

Concluding Remarks (DOE)

${ }^{16}$ Panelist list from original schedule updated to depict day-of revision. 


\section{Appendix B. Attendees}

Fifty stakeholders in the data center and hydrogen and fuel cells space attended the meeting, covering the following organizations:

- Air Liquide Hydrogen Energy

- Argonne National Laboratory

- Ballard Power Systems

- Cummins Inc.

- Daimler AG

- Doosan Fuel Cell America

- Facebook

- FuelCell Energy Inc.

- General Motors

- Google

- Hewlett Packard Enterprise

- Hexagon Purus LLC

- Hydrogenics USA, Inc.

- Keylogic

- Microsoft

- National Energy Technologies Laboratory

- National Renewable Energy Laboratory

- OCO, Inc.

- OxEon Energy

- Pacific Northwest National Laboratory

- Power Innovations International Inc.

- QTS Data Centers

- Sandia National Laboratories

- Schneider Electric

- Toyota Motor North America

- University of California, Irvine

- University of Washington

- U.S. Department of Energy/Fuel Cell Technologies Office

- U.S. Department of Energy/Federal Energy Management Program

- Worthington Industries 


\section{Appendix C. Breakout Session Topics}

\section{0:30 a.m.-12:00 p.m.: Breakout Session I}

Considering "typical" data centers, discuss the most beneficial way hydrogen and fuel cell technologies could be integrated to meet the data center needs. Develop up to three scenarios that cover a range of data center sizes from small, single rack centers to large hyperscale data centers. Discussion should include whether on-site power generation is for prime or backup power, what critical loads are to be powered, power requirements, thermal management considerations, and runtime required for backup power or frequency of fuel delivery in case of prime power. The scenarios could be designed for either new or retrofit data centers. What are the priorities for the on-site generation? What economic, environmental, or other considerations should be met in powering the data center?

\section{3:00 p.m.-4:30 p.m.: Breakout Session II}

Based on the scenarios developed in the morning breakout, discuss how different hydrogen and fuel cell systems could be integrated to meet the data center needs. This could include usage of large externally-located fuel cells or smaller "distributed" systems, as well as high- or lowtemperature fuel cells. Other topics for discussion should include the level of redundancy; power and/or hydrogen distribution requirements in the data center; thermal integration options; fueling options (e.g., natural gas feed, hydrogen delivery, or on-site hydrogen generation); on-site fuel storage requirements with considerations for size, amount, flow rates, etc. When possible, identify where current technology can meet the needs versus barriers and where there is a technology gap that needs to be addressed through further R\&D. 